\title{
EXPERIENCE OF EXTERNAL COLLABORATION IN "ORGANIZATIONAL BEHAVIOR AND CHANGE MANAGEMENT" SUBJECT IN PRACTICAL LESSON
}

\author{
Vicente Guerola-Navarro1, Raúl Oltra-Badenes ${ }^{1}$, Hermenegildo Gil-Gomez ${ }^{1}$, \\ Maria Herrero-Casanova ${ }^{2}$
}

${ }^{1}$ Departamento de Organización de Empresas. Universitat Politècnica de València (SPAIN)

${ }^{2}$ Universitat de València (SPAIN)

\begin{abstract}
University students are used to attend traditional sessions where the teacher explains theoretical lessons, the contents of which are then applied in practical sessions with identical scripts established to follow the same scheme in practice and theory. This scheme of operation has been traditionally followed, but in some cases, it has caused fatigue and lack of motivation to the students.

In the subject "Organizational Behavior and Change Management" (formerly "Comportamiento Organizativo y Gestión del Cambio") in the Degree of Informatics Engineering, we have been getting some feedback from students on how to improve the results of the students learning results [1]. Consequently to the received feedback, we have decided to put into practice the participation of external speakers (with high experience in topics related to the subject) that show students the most important values of the content of the subject learning guide, through dynamic group discussion sessions where different topics from those studied in the theoretical sessions are discussed in practical sessions.

In this paper we propose the participation of external speakers in practical sessions, as a way to break the routine of academic courses (where teacher of the subject is usually the only speaker in both practical and theoretical sessions). We want to assess the impact that this breakage of the routine can cause in the improvement of the student's perception regarding the evolution of the classes.

The second impact that we want to measure is how it affects the motivation of the students, in the practical sessions, the proposal of topics of debate very different from the theoretical themes of the subject, but at the same time directly related to the subject itself.

In summary, the expected result of this practical research activity is the evaluation of how students react to these unexpected practical sessions, in an unexpected environment, and with unexpected speakers. This impact will be measured based on the improvement of the assessment that students show as a result of their practical learning.
\end{abstract}

Keywords: Organizational Behavior, Change Management, Informatics Engineering, Psychology, Group Dynamics, Relationships.

\section{INTRODUCTION}

The objective of this paper is to study how students react to an unexpected practical activity, in the context of the Subject "Organizational Behavior and Change Management". This Subject is (or has been) directed by the authors of this paper in Universitat Politècnica de València (UPV).

This activity, developed as a practical lesson, is considered as unexpected because [2]:

- It has been directed by a different person than the usual teacher (responsible of the Subject). This leading person is a highly qualified professional in the topic in study.

- The topic that has been exposed and discussed into an interactive Group Dynamics, is completely related to the theoretical background acquired in the theory lessons of the Subject, but it is also completely different than the usual topics that the students have been using during the course.

Below are the basic data of the Subject in which the practical exercise has been carried out, and then the profile of the speaker is presented as well as the justification for the choice of this professional. Subsequently, the way in which the practical exercise has been developed, and the perception by the students, which was collected through a survey, is presented. Finally, the conclusions of the authors are presented after reviewing the results obtained in the survey. 


\section{METHODOLOGY}

First there is the need to recap the information about the subject where the project is going to be place. There is also the need for studying the profile of the external speaker that has been identified as the most fitting to the designed activity and the expected output of the experience.

Secondly, the plan for the development of the practise has to be stablished consequently to the objectives of it, looking for the best fitting to the outcome that we are trying to evaluate.

\subsection{The Subject "Organizational Behavior and Change Management"}

The Subject in which context is developed this study is " Organizational Behavior and Change Management ", a Subject qualified as optative, with a load of 4.5 credits, which is taught in the 3rd year of the Degree in Informatics Engineering in the Universitat Politècnica de València (UPV). This study takes part concretely in the campus that UPV has in Alcoi, formerly Escuela Politècnica Superior de Alcoi (EPSA).

Organizational Behavior is the field of study of behavior and psychological processes in contexts related to work. It takes into account individual, group and organizational variables to improve performance [3]. In short it deals with what people do in an organization, facilitating the understanding of the complexity of the interpersonal relationships in which people interact and how that behavior affects the performance of the organization. It covers individual variables such as: perception, learning and change of attitudes, motivation and satisfaction, design and stress at work; group variables such as: group work, group communication, leadership and conflict; and organizational variables such as: politics, climate and culture and organizational change.

When taking the subject, the student must reach the competencies shown in the following list (reflected in the Subject Teaching Guide), all of them belonging to the subject of Organization and Business Management:

- Ability to understand and apply the principles of risk assessment and apply them correctly in the preparation and execution of action plans.

- Ability to integrate Information Technology and Communications solutions and business processes to meet the information needs of organizations, allowing them to achieve their objectives effectively and efficiently, thus giving them competitive advantages.

- Ability to understand and apply the principles and practices of organizations, so that they can act as a link between the technical and management communities of an organization and actively participate in the training of users.

- Locate relevant information from different sources and investigate technological developments in their field of work and related areas.

- Reason in an abstract, analytical and critical way, knowing how to elaborate and defend arguments in their area of study and professional field.

- Know how to apply their knowledge to their work or vocation in a professional way and possess the skills that are usually demonstrated through the elaboration and defense of arguments and the resolution of problems within their area of study.

\subsection{The leading speaker and her professional profile}

One of the two main news from this practical exercise is the leading person who has developed, presented, directed and driven the session. The speaker has been selected due to her specific background and professional experience in the topic "Change Management", representing then half of the global academical load of the Subject.

The speaker, has reached these relevant merits for considering her as ideal speaker for this practice:

- Degree in Psychology from the Universitat Jaume I of Castelló

- Clinical Psychology Specialist via PIR in Hospital Lluís Alcanyís from Xàtiva

- Psychologist of the Alcohol and Tobacco Unit of the Health Department of Alcoi since 2013 (formerly UCA Gandía 2007-2013, CRIS Ontinyent 2005-07)

- Teacher in EVES courses (Escola Valenciana d'Estudis per a la Salut) 
Besides, there are some merits from speaker that make her specifically suitable for leading a session directed to specific groups:

- Speaker for formal sessions at Official Health Centres

- Professional Title of Oboe

- Elementary Grade of Piano

- Councilor of the City Council of Agullent

The main feature that makes the speaker perfectly ideal for the speaking is her psychologist background, and her long specific work in Public Health Hospital focused in Addictions Unit. The speaker and her team are used day to day to work with patients that have lost their strongness and their decision to change the course of their lives due to harmful addictions that have annulled their mind control.

In our Subject, we work on the big topic "Change Management" during half of the Course, and the final hit has been this highly experienced professional showing how in her hard environment she and her team are able to make the patients be confident on their aims in order to start changing the things that make them weak and unable to change and leave their addictions.

Of course, the environment where this professional team is developing this task, is highly sensible and extremely delicate, so the conclusions of the students have been studied having this special feature in context. We are now looking for motivating the students in their final learning path [4].

\subsection{Description of the practical lesson}

As a good practice when a new person enters into an established and dynamic group, the speaker has been introduced, as well as the main objectives of the practice:

- Go deeper into the Change Management area of study from a practical perspective

- Conclude the Change Management slot in the Subject, as eminently practical side of the Organizational Behavior science.

- Introduce the variable of a new leading person, in order to evaluate the impact and the response from the students.

- Introduce a second variable as extremely sensible environment (Addictions) where the speaker is a very experienced professional, and where the Change Management key features are highly impressive and critical. This variable has been also evaluated and measured.

The speaker has also shared with the class her specific experience and her personal interest on participating in this session, not only as a way to share her experiences but also as a way to get feedback from the students for her own psychological and clinical therapy programs and findings.

The first idea has been to get involved the students in what has been designed as an interactive and practical session [5]. That's when the speaker has asked the students to write and to expose one by one their personal answers to two personal questions:

- Why have you decided today to come to the practical session?

- What are you giving up right now?

The answers from the students have shown a great interest on the session, mainly due to their personal interest on psychological topics, but also due to the expectations put into the presence of a new unknown person leading an unknown practical session.

Once ensured that students are completely involved and engaged with the objectives, the speaker has shown the main theoretical background hits for Change Management. The speaker has emphasized the relevance of Motivation as unleashing key feature for adopting changes in live [6]. For that, there is the need for:

1 Want to change

2 Know how to change

3 Believe that change is possible.

Then, the speaker has defined the six steps for the Change adoption [7]: 
1 Precontemplation

2 Contemplation

3 preparation

4 Action

5 Maintenance

6 Relapse

Once the students have presented their interests, and all the participants have reviewed the theoretical background, the speaker has presented a new scientific and promotional video for a local campaign driven through the Public Healthy Service for the World day without smoking. This video has been the trigger for the practical side of the session, a deep and interactive brainstorming where teacher, speaker, and students have come into debate for discussing about which are the key hits for engaging with the people who is doubting about if to start changing, how to start, who to ask help for starting, how to consolidate the earnings, and how to re-engage if relapses occur during the change.

The presence of the external speaker, and the external topic (not included in the core themes of the Subject but closely related to those themes), have been the difference that have make very different the way the practical session has been developed, how the discussion has been conducted and the outputs that have been got in the brainstorming.

\subsection{Perception by the students of the subject "Organizational Behavior and Change Management"}

The survey that was designed and presented to the students was composed of 9 questions shown below:

1 This practice has improved the understanding of the subject.

2 This practice is more useful / valuable than the previous ones.

3 This practice complements and reinforces well the previous ones.

4 I value very positively having had an external speaker in this practice outside the University.

5 I value very positively in this practice its focus on a different subject from the rest of the practices of the subject.

6 This practice shows the interest of the teacher for our learning

7 I want to have more practices like this in this subject and in other subjects.

8 I would recommend to the students of this subject that they attend and participate in this practice.

9 I would go back to the practice if I had the chance, for what it has given me in terms of personal and professional development.

The answers to the questions in this survey correspond to a Likert scale [8], from 1 to 5 , in which the meaning of each answer is:

1 Totally agree

2 Agree

3 Medium term (neither agreement nor disagreement)

4 Disagree

5 Strongly disagree

The survey was passed to the students at the end of the practical exercise, when they had already completed all the rest of previously scheduled practices, and acquired the knowledge imparted in the theoretical lessons. It was filled by 11 students, of the 11 enrolled in the Subject, so the sample is representative of the group of students of the subject (90\%). There are also three more students that have exemption and not need/must to attend classes.

Of the answers, none of them were eliminated, since all of them have the answers marked in the correct form. With this, the analysis was carried out on a total of 10 surveys filled out by the students. 


\section{RESULTS}

The results collected in the surveys are those shown below in the following table.

Table 1. Results collected in the surveys

\begin{tabular}{|l|c|c|c|c|c|}
\hline & $\begin{array}{c}1 \\
\text { Totally } \\
\text { agree }\end{array}$ & $\begin{array}{c}2 \\
\text { Agree }\end{array}$ & $\begin{array}{c}3 \\
\text { Medium } \\
\text { term }\end{array}$ & $\begin{array}{c}4 \\
\text { Disagree }\end{array}$ & $\begin{array}{c}5 \\
\text { Strongly } \\
\text { disagree }\end{array}$ \\
\hline $\begin{array}{l}\text { This practice has improved the understanding of the } \\
\text { subject. }\end{array}$ & 5 & 4 & 1 & 0 & 0 \\
\hline $\begin{array}{l}\text { This practice is more useful / valuable than the } \\
\text { previous ones. }\end{array}$ & 3 & 4 & 3 & 0 & 0 \\
\hline $\begin{array}{l}\text { This practice complements and reinforces well the } \\
\text { previous ones. }\end{array}$ & 6 & 3 & 1 & 0 & 0 \\
\hline $\begin{array}{l}\text { I value very positively having had an external speaker } \\
\text { in this practice outside the University. }\end{array}$ & 10 & 0 & 0 & 0 & 0 \\
\hline $\begin{array}{l}\text { I value very positively in this practice its focus on a } \\
\text { different subject from the rest of the practices of the } \\
\text { subject. }\end{array}$ & 8 & 1 & 1 & 0 & 0 \\
\hline $\begin{array}{l}\text { This practice shows the interest of the teacher for our } \\
\text { learning }\end{array}$ & 10 & 0 & 0 & 0 & 0 \\
\hline $\begin{array}{l}\text { I want to have more practices like this in this subject } \\
\text { and in other subjects. }\end{array}$ & 10 & 0 & 0 & 0 & 0 \\
\hline $\begin{array}{l}\text { I would recommend to the students of this subject that } \\
\text { they attend and participate in this practice. }\end{array}$ & 6 & 3 & 1 & 0 & 0 \\
\hline $\begin{array}{l}\text { I would go back to the practice if I had the chance, for } \\
\text { what it has given me in terms of personal and } \\
\text { professional development. }\end{array}$ & 6 & 4 & 0 & 0 & 0 \\
\hline
\end{tabular}

Source: self-made.

As there can be observed in the table above, the $50 \%$ of the students strongly agree on the beneficial attendance of the practice for the proper understanding of the subject. If we consider that the $40 \%$ of the students also agree on that, and only the $10 \%$ have not decided if to agree or to disagree, it results on a $90 \%$ of students agreeing or strongly agreeing of the effect of the practice on a good understanding of the subject.

The $30 \%$ of the students consider that this practice is highly more useful than the previous ones. The $40 \%$ consider the same but with lower emphasis, and the $30 \%$ are in mid-term point.

Considering the practice as complementary for the previous ones, the $60 \%$ are completely aligned, with $30 \%$ of students just agreeing on it and $10 \%$ with no clear decision.

There are three questions where students have clearly agreed with $100 \%$ of Strongly agree answers:

- I value very positively having had an external speaker in this practice outside the University.

- This practice shows the interest of the teacher for our learning

- I want to have more practices like this in this subject and in other subjects.

On other hand, the $80 \%$ of the students value very positively in this practice its focus on a different subject from the rest of the practices of the subject. The $10 \%$ just agree on it, and the rest $10 \%$ only show indifference.

The $60 \%$ of the students would highly recommend to the students of this subject that they attend and participate in this practice. The $30 \%$ would recommend it, and the $10 \%$ have not decided yet.

Finally, the $60 \%$ would very happily go back to the practice if they had the chance, for what it has given me in terms of personal and professional development, and the $40 \%$ would also go back to the practice. 


\section{CONCLUSIONS}

After analyzing the responses to the surveys carried out, it can be concluded that the acceptance of the style of practical session put in effect in this Subject for this group of students has been very positive.

In all questions, there was a majority of favorable responses, with none of them showing disappointing with the practice. There are only four questions with $10 \%$ in the Mid Term (not agree, not disagree) acceptance, and only one question on $30 \%$ in the Mid Term acceptance (mainly due to the high acceptance that the previous practices have also had). The rest of the questions have all received majority agree/strongly agree, showing the high interest that the session have inspired to the students and the high value that the new format have brought to them.

Important to consider that all the practices conducted in this Subject have been designed as group dynamics, with high involvement of the students, highly interactive, and general high acceptance from them, so there is the global conclusion that practical interactive sessions are very well received by students in their understanding of this Subject. In this case, and putting in value the results of the study, it can be concluded that breaking rules with external speakers and external thematic can definitely make the students better understand the Subject Theoretical lessons and then make them put their best interests on the learning.

\section{REFERENCES}

[1] Hortigüela Alcalá, David, Víctor Abella García, and Ángel Pérez Pueyo. "Percepciones del alumnado sobre la evaluación formativa: contraste de grupos de inicio y final de carrera" Vol. 13 (3), Octubre-Diciembre 2015, 13-32 ISSN: 1887-4592

[2] PRETORIUS, Werner M. Cognitive behavioural therapy supervision: recommended practice. Behavioural and Cognitive Psychotherapy, 2006, vol. 34, no 4, p. 413-420. Doi:10.1017/S1352465806002876

[3] Robbins, S. P., Judge, T. A., \& Pineda Ayala, T. A. Comportamiento organizacional. México: Pearson Educación, 2013.

[4] TAPIA, J. Alonso. Motivación para el aprendizaje: la perspectiva de los alumnos. La orientación escolar en centros educativos, 2005, p. 209-242.

[5] COOPER, James M.; BULL, Glen L. Technology and teacher education: Past practice and recommended directions. Action in Teacher Education, 1997, vol. 19, no 2, p. 97106. Doi: $10.1080 / 01626620.1997 .10462871$

[6] WALSTON, M.; BOUNDY, D. Querer no es Poder. Cómo comprender y superar las adicciones. México, Ed. 1991.

[7] MILLER, William Richard; ROLLNICK, Stephen. La entrevista motivacional: ayudar a las personas a cambiar. Grupo Planeta (GBS), 2015.

[8] LIKERT, Rensis. A technique for the measurement of attitudes. Archives of psychology, 1932. 